of hopeless difficulty. Nevertheless we are able, by attending to the condition of similarity of the motion in different cases, to compare the viscosities of the different gases for as many groups of corresponding pressures as we please. Setting aside certain minute corrections which would have vanished altogether had the moment of inertia of the vibrating body been sufficient to make the time of vibration sensibly independent of the gas, as was approximately the case, the condition of similarity is that the densities shall be as the log decrements of the arc of vibration, and the conclusion from theory is that when that condition is satisfied, then the viscosities are in the same ratio. Pressures which satisfy the condition of similarity are said to "correspond."

It was found that on omitting the high exhaustions, the experiments led to the following law :-

The ratios of the viscosities of the different gases are the same for any two groups of corresponding pressures. In other words, if the ratios of the viscosities of a set of gases are found (they are given by the ratios of the log decrements) for one set of corresponding pressures, these pressures may be changed in any given ratio without disturbing the ratios of the viscosities.

This law follows of course at once from Maxwell's law, according to which the viscosity of a gas is independent of the pressure. It does not however by itself alone prove Maxwell's law, and might be satisfied even were Maxwell's law not true. The constancy however of the log decrement, when the circum. stances are such that the molar inertia of the gas may presumably be neglected, proves that at any rate when the density is not too great that law is true; and the variability of the log decrement at the higher pressures in all but the very light gas hydrogen is in no way opposed to it, though Mr. Crookes's experiments do not enable us to test it directly, but merely establish a more general law, which embraces Maxwell's as a particular case.

The viscosities referred to air as unity which came out from Mr. Crookes's experiments were as follows :-

$$
\begin{array}{llllllll}
\text { Oxygen } \ldots & \ldots & \ldots & \ldots & \ldots & \ldots & \ldots & \text { r.117 } \\
\begin{array}{l}
\text { Nitrogen and carbonic oxide } \\
\text { Carbonic anhydride }
\end{array} & \ldots & \ldots & \ldots & 0.970 \\
\text { Hydrogen } & \ldots & \ldots & \ldots & \ldots & \ldots & \ldots & 0.823 \\
\text { Hydro } & \ldots & \ldots & 0.500
\end{array}
$$

The viscosity of kerosoline vapour could not be accurately deduced from the experiments, as the substance is a mixture, and the vapour-density therefore unknown. Assuming the relative viscosity to be 0.0380 , the vapour-density required to make the experiments fit came out $3^{\circ} 408$ referred to air, or $49^{\circ} 16$ referred to hydrogen.

When once the density is sufficiently small, the log decrement may be taken as a measure of the viscosity. Mr. Crookes's tables show how completely Maxwell's law breaks down at the high exhaustions, as Maxwell himself foresaw must be the case. Not only so, but if we take pressures at those high exhaustions which are in the same ratios as "corresponding " pressures, the $\log$ decrements in the different gases are by no means in the ratios of the densities.

It would appear as if the mechanical properties of a gas at ordinary pressures and up to extreme exhaustions (setting aside the minute deviations from Boyle's law, \&c.) were completely defined by two constants, suppose the density at a given pressure and the coefficient of viscosity; but that specific differences come in at the high exhaustions at which the phenomena of "ultra-gas" begin to appear; and that to include these, an additional constant, or perhaps more than one, requires to be known.

\section{ANIMAL REMAINS IN THE SCHIPKA CAVERN}

$\mathrm{N}$ December 6, 1880, Prof. Schaaffhausen gave a lecture to the Lower Rhire Society in Bonn, on the discoveries made by Prof. Maschke in the Schipka Cavern, near Stramberg, in Moravia. In this cavern were found remains of Bos, Ursus, Elephas, Rhinoceros, Leo, and Hyæna, besides roughly-hewn implements of quartzite, basalt, and flint, and some incisor teeth of Ursus, which were cut into on both sides at the beginning of the crown, perhaps because people did not yet know how to bore a hole into the root. Carbonised animal bones in numerous small fragments were met with. A solitary human relic was found in a protected place at the wall of a side passage of the cavern, and near a fireplace. It was the fragment of a lower iaw, amid ashes and inter-breccia of lime. The same layer con- tained mammoth remains and stone implements. Of the jaw only the front part with incisors, one canine, and the two premolars, of the right side remained. The latter three teeth were still in the jaw undeveloped, but were visible, because the front wall of the jaw was wanting. The largeness and thickness of the jaw, first of all, were remarkable. The teeth-development corresponds to the first year of life, but the jaw and the teeth are as large as those of an adult. As is the rule with man, the first pre-molar seemed nearest being cut ; next to it came the canine, then the second pre-molar.

The height of the jaw in the line of symphysis measures, to the alveolar border, $30 \mathrm{~mm}$., to the end of the incisors $39 \mathrm{~mm}$. (In the jaw of a child seven years old the corresponding measurements were $23 \mathrm{~mm}$. and $30 \mathrm{~mm}$.; in a girl nine years old $24 \mathrm{~mm}$. and $33 \mathrm{~mm}$.; in a boy of $12,22 \mathrm{~mm}$. and $31 \mathrm{~mm}$. The jaws of eight adults measured in height, to the alveolar border, on an average, $3 \mathbf{r} \mathbf{~ m m}$.) The jaw fragment, at its lower border, in the line of symphysis, is $14 \mathrm{~mm}$. thick; under the canine tooth the thickness is $15 \mathrm{~mm}$. (In an ordinary adult jaw the thickness in the line of symphysis is about II mm.) Now when the cutting surface of the incisors is placed horizontally, the under part of the prognathous jaw bends so much back that one misses the chin as a prominence. A vertical from the front alveolar berder falls 4 to $5 \mathrm{~mm}$. in front of the lower border of the jaw. The hinder surface of the symphysis is placed obliquely, as occurs in a high degree in the anthropoids, and in lower degree in savage races, but has also before been observed in fossil human remains, as in the jaw of La Naulette, to which this jaw from the Schipka Cavern has much similarity. The form of the incisors is adapted to the thick prognathous jaw ; the broadest part of the root measures from front to back $8 \frac{1}{2} \mathrm{~mm}$., whereas the ordinary measurement here is $6 \mathrm{~mm}$. Further the teeth are bent convex in front. The curvature corresponds to a radius of $27 \mathrm{~mm}$. The spina mentalis interna is absent, and instead there is, as in the anthropoids, a cavity, at the lower border of which some unevenness can easily be felt. The prominences for attachment of the Musculi digastrici are well marked, implying a correspondingly strong development of the antagonistic muscles, the masticatory. All these features were also met with on the jaw of La Naulette, but more developed. It is probable that the jaw of the Schipka Cavern also had the pithecoid peculiarity, that its tooth-line was not horizontal, but rose from the premolars to the incisors, and its body was higher in front than at the sides, because the cutting-surface of the outer incisors sinks obliquely outwards. The size of the canine tooth is remarkable, its enamel crown being $13^{\circ} .5 \mathrm{~mm}$. long. (In the fossil lower jaw of Uelde the canine tooth exceeds the premolars about $3.5 \mathrm{~mm}$. According to measurement on ten European adult skulls with the teeth hardly, or not at all, worn down, the crown of the canine tooth was ir ${ }^{\prime} 5 \mathrm{~mm}$. long. Only once, among more than fifty skulls, was it found $14 \mathrm{~mm}$.) It cannot well be supposed that this jaw, caught in dentition, belonged to an individual of giant growth, since in such individuals the excessive growth, according to Langer, first begins about nine to ten years of age. The assumption that some pathological cause had hindered the development of the three teeth that remained within the jaw seems quite groundless. As little can we suppose that in the prehistoric time the teeth development was retarded, and that the change of teeth occurred at a later age, since a quicker development corresponds to a lower organisation. (All mammals come into the world with teeth, and the orang changes its teeth sooner than man.)

The size of the front part of the jaw however may in itself be regarded as pithecoid; and there is more reason for this in that other pithecoid characters are present. The aspect of the grey-yellow bone with small dark branching spots on it is met with often in cavern bones. The enamel of the teeth is quite like that of the Quaternary cave animals; it shows longitudinal fissures with dark infiltration; while near these appear bluish, and in some places yellow, spots.

\section{SOME REMARKS ON PERIPATUS EDWARDSII, BLANCH.}

SINCE I learnt from Mr. Moseley's notes on the species of Peripatus (Ann. and Mag: of Nat. Hist., v. ser., iii., 263), that one of them, referred by Grube to $P$. Edwoardsii, had been obtained from this country, in the neighbourhood of Colony Tovar ${ }^{1}$ ), I tried to get specimens of this highly interesting ${ }^{I}$ Not Colony fowar, as the name is printed in Mr. Moseley's paper. 
animal. But all my efforts being unsuccessful for a long time, I finally lost all hopes, and the pressure of other business, scientific and not scientific, caused me to lay the matter on the shelf, little thinking that I had my desideratum close at my elbows.

There is within our University building a large square yard, where stones, old bricks, and other such refuse had been accumulating in the course of years. About a month ago it was fortunately resolved to transform this very ngly place into a garden, and $I$ engaged the workmen to bring me any kind of animal they might turn up under the heaps of rubbish. How great was my sitisfaction to find in the very first gatherings half a dozen of Peripatus among some common beetles, centipedes, and earthworms! I offered immediately a prize for every other specimen of the former, and so good proved the locality that in a few days I was in possession of more than fifty of these unexpected cives academici of ours, the supply being apparently far from exhausted. ${ }^{1}$

As there are still some points in the natural history of Peripatus which are not well settled, I beg leave to offer the following remarks. based on the careful examination of living or dissected specimens.

The number of females appears to be much larger than that of males; for among fifty-three specimens I found only five males, which are about half the size of the females. These are

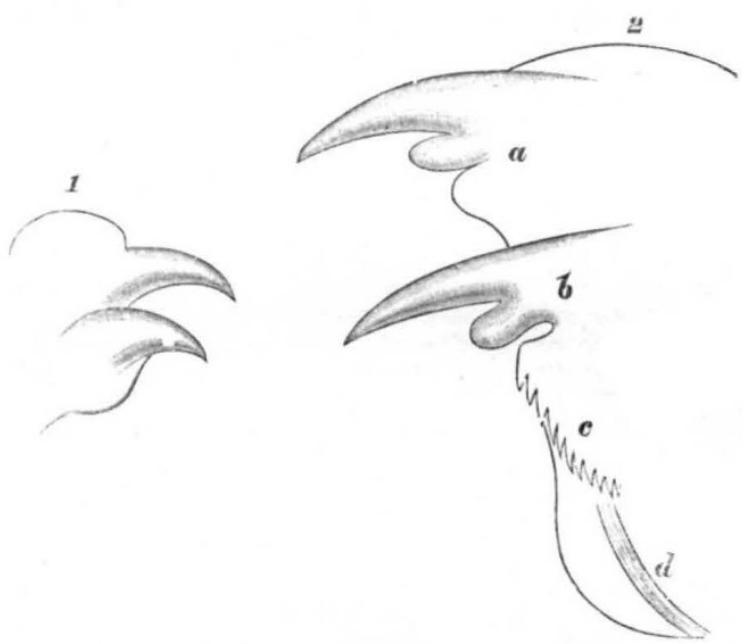

FIG. .

FIG. 2.

FIG. I.-Horny claws of one of the foot-jaw' in the young animal wh.n born Frg. 2. - The same, from an adult female. $a$, first claw; $b$, second claw; $c$, horny saw; $d$, pigment-line.

sometimes nearly I decimetre long, 5 to 6 millimetres broad, and somewhat tapering on both extremities. The colour is brownish black, with a diffused black line on the middle of the back; the ventral side is dark flesh-coloured. Full-grown animals have thirty-one pairs of ambulatory feet, the new-born animals have but twenty-nine ; the length of the latter is about 25 millimetres, their breadth two, the tentacles measure $3 \mathrm{~mm}$. ; their colour is reddish, with a line of somewhat lozenge-shaped figures of a paler tint running down the middle of the back.

I twice observed the birth of a young Peripatus. The mother raised slightly the hind part of the body, moving it slowly from one side to the other. After some minutes the head of the embryo protruded from the sexual porus, and in half an hour half the body came out, twisting around all the while in every direction. The old animal remained rather quiet, moving occasionally its head, but not crawling about. As soon as the process was advanced thus far, the young Peripatus clung with its feet to the nearest surface in its reach ; and the mother walking off, the hind part of the embryo came forth in a few seconds.

In one case a young Peripatus was born in a tuubler of water, in which I had placed the mother, in order to kill it in an extended condition, as recommended by.Moseley in his well-known paper in the Phil. Transactions. I did not see the birth, but found the young animal already crawling on the back of the mother, and there floated in the water close by a very thin skin of

I Those desirous of obtaining specimens from me in exchange for books or papers on zoological topics, will be good en ough to write to me. the size of the young animal, exhibiting its whole form, even the tentacles. I suppose it must have been shed soon after birth, but have failed hitherto to see anything alike in the other cases of birth, which I watched very carefully.

I could not well make out the number of articulations in the tentacles; there are, however, more than thirty in those of the young animal, having each a ring of short spiny bristles at the base. The slime-glands of the young Peripatus are already well developed. It has twenty-nine pairs of feet; and as the adult animal has never more than thirty-one, there must be specimens with the intermediate number of thirty, which would settle $\mathrm{Mr}$ Moseley's question (Ann. and Mag. of Nat. Hist., l. c.) It is probable that Peripatus goes through several moultings, and that the new feet then make their appearance.

This may be further surmised from the development at the horny claws of the foot-jaws, which are simple, and not indented in the young animal, but of a much more complicate structure

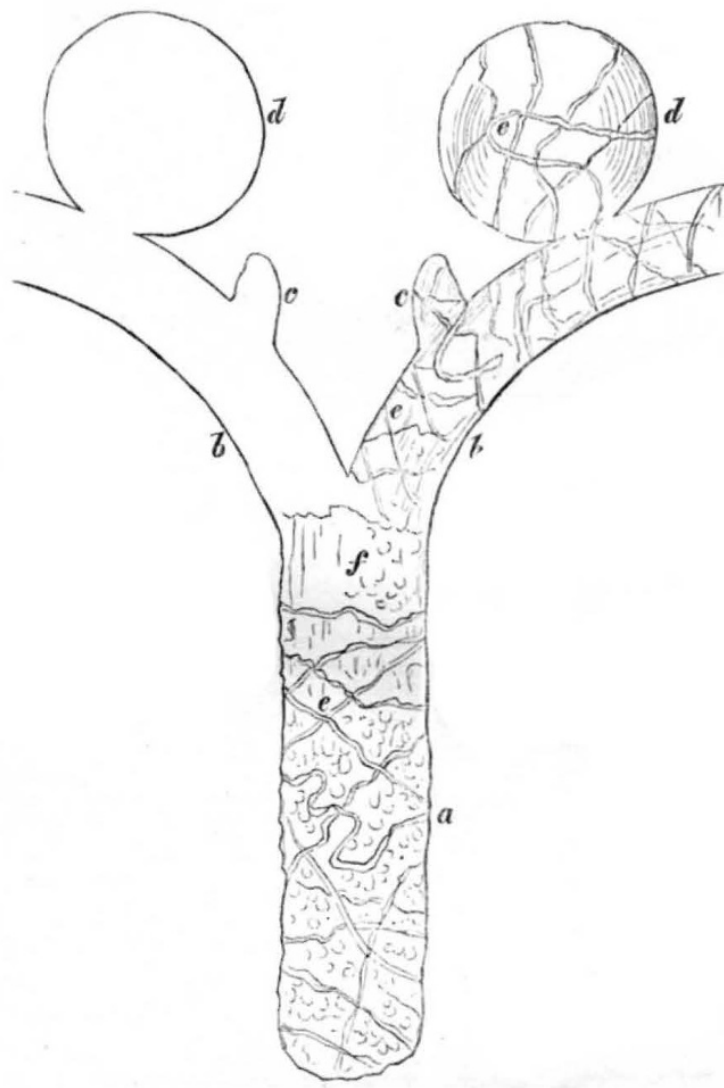

FIG. 3.-Schematic sketch of ovary (a), beginning of oviducts (b), cæca (c), receptacula seminis $(d)$, covered by tracheal tubes $(e), z$ ne of ovary without tracheal tubes $(f)$.

in the old one. The annexed figures represent these claws in both conditions.

In the adult animal there is first a large pointed tooth, then follows a shorter one, which is obtuse; both are formed appa. rently of three to four superposed lamellæ, the outlines of which are distinctly visible by changing the focus of the microscope. The second maxillary claw has likewise two teeth of the same shape and structure, but bears behind them a kind of saw, com. posed of ten small teeth of the same amber-yellow colour as the inner parts of the larger teeth. This saw is followed by an oblique line of a yellowish pigment, perhaps the rudiment of another developing saw, or a reservoir of horny matter.

The structure of the sexual organs may deserve a few remarks. There can be no doubt that the sexes are separate. The male organs are very much like those described by Moseley in his paper; only the vesicula seminales are not nearly so spirally 'wisted as in his figure on plate lxxii. The testes contain spermatozoa of the same shape as those of P. Capensis. I noticed 
that the slime-glands were much less developed in the males than in the females.

The structure of the female organs in our Caracas species agrees pretty well with Prof. Hutton's drawings ( $A n n$. and Mag. of Nat. Hist., iv. ser., vol. I8, pl. xvii., fig. 8) ; but I am not prepared to accept his interpretation. The following sketch will give an idea of what I saw.

Moseley's Fig. I on PI. 1xxiv. is very different from the shape of the ovary in our species; nor can I well understand the existence of ova on the outside of the ovary as they appear in his drawing. The ovary in $P$. Edwardsii is rather long, and abundantly covered by fine tracheal tubes, with the exception of a narrow zone close to the branching out of the oviducts. I could not satisfy myself as to its being divided by a septum, nor could I find any ova in it; most likely it is not now the right time. At a very short distance from the beginning of the oviducts there is a kind of obtuse cacum on each of them, which is followed by a spherical body covered by tracheal tubes. These bodies are the organs described by Prof. Hutton as testes.

There is however in our species no trace of what he takes for vasa deferentia, the spherical body adhering directly to the oviduct. Its wall is of considerable resistance, and bursts only under great pressure, giving issue to an immense number of thin rod-like corpuscula, which soon after begin to move slowly in the surrounding water. They are of course spermatozoa which have lost their nuclei, and the spherical body can therefore be nothing else but a receftaculum seminis.

The oviducts of three specimens which I dissected contained very few embryos; in one there was only one in each oviduct, in the others there were two. They were fully developed, and occupied the part of the oviducts close to the vulva. It would appear from this that the time of reproduction is now almost over; further observations will show whether there is really such a periodicity in our species.

It is probable that the oviducts of $P$. Edzuardsii never present the shape of string; of sausages, as seen by Mr. Moseley in $P$. Capensis, the embryos being so considerably larger.

Animals thrown alive into alcohol pour forth from their slimeglands first the viscid substance contained in these ; then there comes out a slightly reddish matter, which dissolves in the alcohol, giving it the same colour.

With respect to all other points I can only confirm $\mathrm{Mr}$. Moseley's statements. 1 keep alive a colony of Peripatus of both sexes in the hope to have once a chance to observe the copula.

I cannot conclude these remarks without confessing that I am not at all quite sure whether our Peripatus is really $P$. Edzuardsii, as the figure of this species in Nicholson's "Manual of Zoology" (5th edit. p. 315), which is said to be after Grube, does not agree well with my living specimens. Grube's original paper I cannot consult here. It may be however that he made his drawing from a contracted alcoholic specimen. A. ERNS'

The University, Carácas, January 16

\section{ACOUSTICS IN CHINA}

THE following letter to Prof. Tyndall has been sent to us for publication by the writer, Mr. Fryer. It will be seen that a really scientific modern correction of an old law has singularly turned up from China, and has been substantiated with the most primitive apparatus. Dr. W. H. Stone, to whom the letter has been submitted, has kindly appended a note.

To Prof. Tyndall, Ll.D., F.R.S., \&c.

DEAR SiR,-My friend Mr. Hsii has brought some interesting facts relating to acoustics before my notice. As he is the father of the native official who translated with me your work "On Sound," and as he refers particularly to that work, I venture to forward you a translation of his remarks, in the hope that you will satisfy his mind on a subject in which he takes such deep interest. He says :-

"In ancient Chinese works on music it is stated that strings or pipes produce an octave or twelve semitones higher or lawer by halving or doubling their length.

"In a work written during the Ming dynasty by Chen-toaiyoh it is stated that this rule will only hold good with strings, but not with open pipes such as the flute or flageolet.

"Some years ago I tried to investigate the cause of this difference and its exact amount. A round open brass tube, say nine inches long, gave a certain note by pressing the end of it against the upper lip and blowing through an embouchure made there. Cutting off half the tube, the remaining four and a half inches would not sound the octave; but by cutting off half an inch more, thus leaving four inches in length, the octave was sounded accurately. This experiment was tried on tubes of various lengths and diameters with a similar result, viz. that four-ninths of the length always sounded the octave more or less exactly. Looking at a foreign keyed flute I noticed the same principle carried out in the arrangements for producing octaves. I could not however see the reason why open pipes should not follow the same rule as strings and closed pipes.

"When I read the translation of Prof. Tyndall's treatise 'On Sound,' I was surprised to find the old Chinese idea strictly maintained. It says (p. 214): 'In both stopped and open pipes the number of vibrations executed in a given time is inversely proportional to the length of the pipe,' \&c. According to this, as the octave of any note has to execute exactly double the number of vibrations in a given time, an open pipe ought to be exactly halved to make it sound an octave higher. This I have shown to be erroneous by my experiments.

"Fearing that I have misunderstood the English professor's meaning, $X$ beg that he may be written to on this subject, and that my doubts may be thereby cleared up. What I want to know is the exact proportion in length that exists between any open pipe and a pipe of similar diameter sounding its octave higher. Also the exact proportions in length for each of the open pipes sounding the twelve semitones which form a scale of one octave. If the length forming the octave in open pipes does not agree with the length for strings or closed pipes, then the lengths of all the pipes giving intermediate notes must also differ. How are these lengths to be calculated? Can they be expressed by any mathematical curve or formula? Why does not the same rule hold good for open pipes as for strings or stopped pipes? I have a theory of my own, but I do not feel sufficient confidence in myself to make it public until I have bestowed more thought and attention upon it. In the meantime I shall be glad if any foreign scientists can enable me to understand this interesting and important subject. The theory and practice of music in China has gradually become vitiated through errors in the construction of musical instruments, and I am therefore desirous of having a scientific basis upon which a reformation may be effected."

There is no treatise on music or acoustics that $I$ can find which throws any light on these interesting questions, and I shall therefore deem it a great favour if you will direct me to any work that will enable me to satisfy the eager inquiries of my native friend.

I send by book-post a pamphlet for your kind acceptance, containing an account of the Department for the Translation of Scientific Books at the Kinagnan Arsenal. You will see that your " Notes on Light" are now published in Chinese. A copy will be forwarded to you shortly. Your " Heat a Mode of Motion" I hope to begin to translate at no very distant time. Your "Notes on Electricity" in (hinese will be published shortly.

$$
\begin{aligned}
& \text { I remain, dear Sir, yours faithfully, } \\
& \text { Shanghai, June I, I880 FRYER } \\
& \text { November } 25 \text { th, 1880 }
\end{aligned}
$$

P.S.-I have sent a copy of this letter to the Editor of NATURE, and shall feel greatly obliged if you will forward your reply, if any, to him for publication.-J. F.

MR. FRYER is perfectly correct in his observations. You will find the explanation and formula needed at p. I67 of my little book on Sound, under the heading "Correction of Bernouilli's Law." "It has long been known," I there say, "that if an open pipe be stopped at one end its note is not exactly an octave below that given by it when open, but somewhat less, the interval being about a mojor seventh instead of an octave."

Then follows the mathematical statement, from which the corrections needed by Mr. Fryer could easily be obtained. M. Bosanquet's excellent experimental investigation of the subject is briefly described. His results give the correction for the open end of the pipe as 635 of radius of pipe, and $59 r$ for the mouth. Mr. Bosanquet remarks that in Bernouilli's theory the hypothesis is made that the change from the constraint of the pipe to a condition in which no remains of constraint are to be perceived takes place suddenly at the point where the wave system leaves the pipe. It is however evident that the diverg. ence which takes place may be conceived of as sending back to the pipe a series of reflected impulses, instead of the single 